\title{
Cultivation to improve in vivo solubility of overexpressed arginine deiminases in Escherichia coli and the enzyme characteristics
}

Ying Wang and Yue-Zhong Li*

\begin{abstract}
Background: Overexpression of foreign genes in Escherichia coli cells is an efficient means to obtain recombinant proteins. The technique is, however, often hampered by misfolding, degradation, aggregation and formation in inclusion bodies of products.

Results: In this study, we reported that in vivo solubility of overexpressed arginine deiminases (ADI) improved by changing the cultivation conditions. ADI is enzymes that convert L-arginine to L-citrulline. After codon optimization, we synthesized the ADI gene of Pseudomonas putida and constructed it for overexpression in E. coli cells. The rADI products were mainly in inclusion body forms. We performed a series of optimization to enhance solubility of the protein. Co-expression with the GroES-GroEL chaperone team increased approximately 5-fold of the rADI activity. In addition the combination of L-arginine and D-glucose in the Luria-Bertani (LB) growth medium further increased the total activity to about 15 times. Separate L-arginine and D-glucose or the addition of other saccharides or amino acids had no such effects. The solubilization effects of the combination of L-arginine and D-glucose were further confirmed in the overexpression of another ADI from Listeria welshimeri. The enzymatic and conversion characteristics of the rADI products were further determined.
\end{abstract}

Conclusions: Combined addition of L-arginine and D-glucose in the LB medium significantly improved in vivo solubility of rADI proteins. The present study suggested a new strategy to increase the solubilization of overexpressed recombinant proteins in E. coli cells.

Keywords: Arginine deiminase, Heterologous expression, Escherichia coli, Solubilization, Cultivation, Conversion, L-arginine, L-citrulline

\section{Background}

Escherichia coli cells are an efficient factory to produce foreign proteins because of high-cell density, well-known genetics background and the simplest genetic manipulation [1,2]. However, high expressions of recombinant proteins often result in misfolding, aggregation, degradation, low activity and formation in inclusion-bodies of products, which greatly hampers associated researches and industrial and medical applications [2-6]. In order to improve the solubility of recombinant proteins, many strategies have been developed, such as co-expression with chaperones, secretion expression of recombinant proteins and

\footnotetext{
* Correspondence: lilab@sdu.edu.cn

State Key Laboratory of Microbial Technology, School of Life Science, Shandong University, Jinan 250100, P. R. China
}

protein fusion techniques $[7,8]$. In this study, we reported that combined addition of D-glucose and L-arginine in the Luria-Bertani (LB) medium to cultivate $E$. coli cells were efficient to enhance the solubility of recombinant arginine deiminases.

Arginine deiminase (EC3.5.3.6; ADI) hydrolyzes Larginine to L-citrulline, releasing ammonia. Arginine deiminase, combining with ornithine transcarbamylase and carbamate kinase forms the arginine deiminase pathway [9], which is widely distributed in the microorganisms that are able to utilize arginine as an energy source [10]. By depleting extracellular supply of L-arginine, ADI is a potential anti-tumor agent for its efficient inhibition effects on the growth of arginine-auxotrophic tumor cells, especially hepatocellular carcinomas and melanomas [10-12]. ADI is also considered a useful producer 
of L-citrulline at industrial scale [13]. So, many ADI genes from different sources, including Mycoplasma arginini [11,12,14-16], Pseudomonas plecoglossicida [17], Lactococcus lactis [18], Streptococcus sanguis [19] and Giardia intestinalis $[20,21]$ have been cloned and expressed in $E$. coli cells. However, the recombinant ADI proteins were mainly existed in inclusion body forms, which is a bottleneck in its research and development. We overexpressed arginine deiminases from different resources in the $E$. coli cells for industrial conversion L-arginine to L-citrulline. Our recombined ADI proteins named $\mathrm{ADDI}$, were similarly mostly in inclusion bodies. In this study, we made comprehensive optimizations to improve solubility of the rADI proteins and found that the combined addition of L-arginine and D-glucose in Luria-Bertani (LB) medium distinctly increased the in vivo solubility of rADI in E. coli cells. We studied the enzymatic and conversion characteristics of the rADI.

\section{Results}

Construction and expression of ADI gene in E. coli

The arginine deiminase of $P$. putida had been studied due to its characteristics by purification from its original host [22]. Because of its high specific activity $(58.8 \mathrm{U} / \mathrm{mg})$ and in-vitro solubility, we selected the enzyme to investigate its potential in industrial conversion from L-arginine to L-citrulline. We optimized the gene sequence according to the codon frequency table of $E$. coli BL21(DE3) using the "codon randomization" strategy [23] and synthesized it. The artificial ADI gene (Figure 1) was constructed into different expression plasmids, including pET-30a $(+)$, pBAD/gIIIA, pColdTF and pGEX-6P-1, for overexpression in E. coli BL21(DE3). After a normal optimization process according to the previous report [24], $0.1 \mathrm{mM}$ IPTG and $0.04 \% \mathrm{~L}$-arabinose incubated at $16^{\circ} \mathrm{C}$ were used to induce the rADI expression in E. coli cells. These expression plasmids, except pET-30a(+), exhibited nearly no solubility

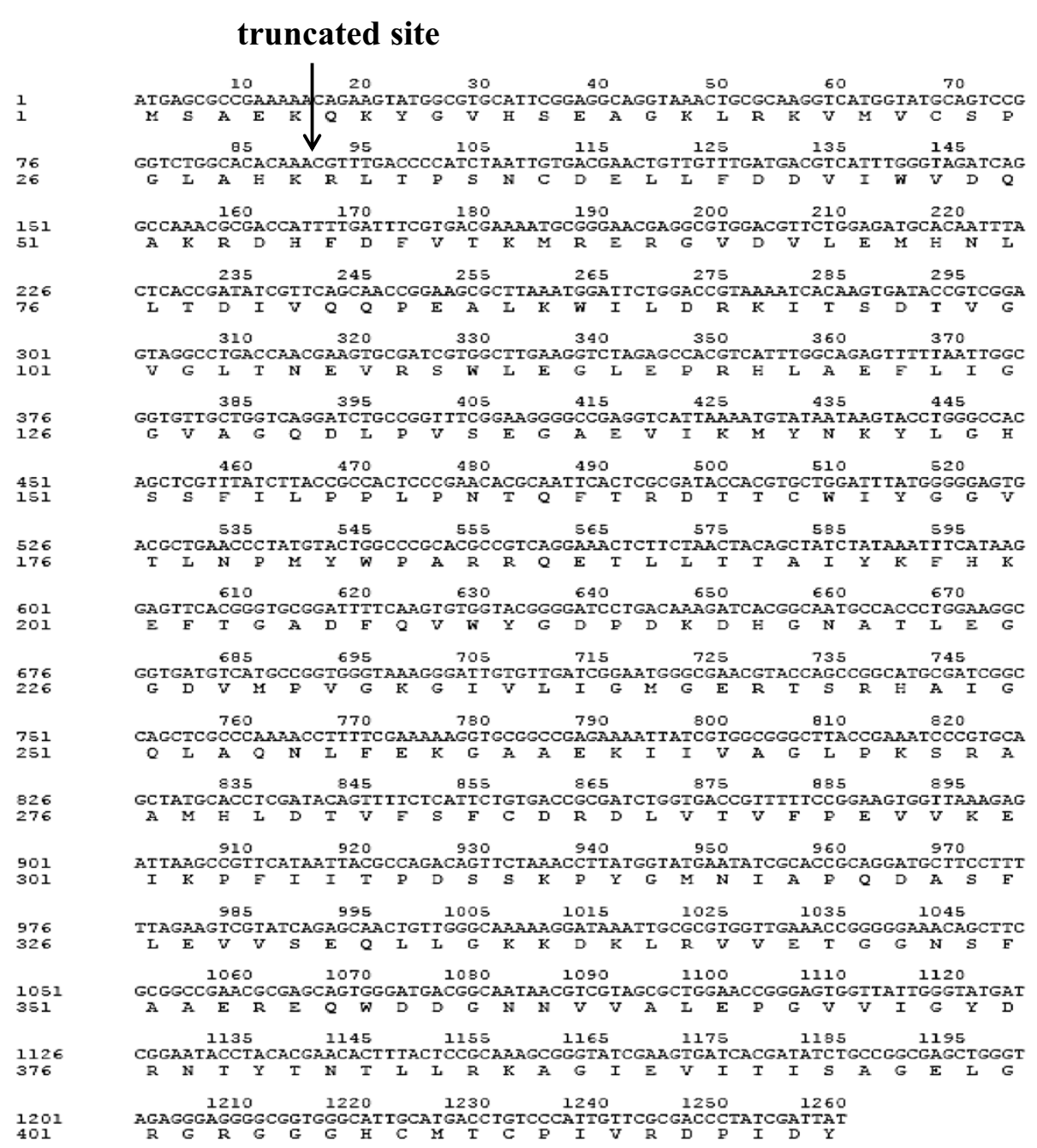

Figure 1 Nucleotide and corresponding amino acid sequences of the artificial ADI gene. The black arrow indicates the truncation site of T-rADI. 
and enzymatic activity to hydrolyze L-arginine to Lcitrulline. The pET30a-ADI produced overexpressed rADI proteins. However, there was only a weak corresponding band (approximately $53 \mathrm{kDa}$ ) in the soluble fractions (Figure 2A, lane 3), which gave the hydrolytic activity of $0.64 \pm 0.04 \mathrm{U} / \mathrm{ml}$. Most of the expressed proteins were existed in the form of inactive inclusion bodies (Figure 2A, lane 4).

Wen et al. [25] reported that truncation of a noncatalytic region in a 1,3-1,4- $\beta$-D-glucanase from Fibrobacter succinogenes improved enzymatic activity and thermotolerance. The crystal structures of ADI from Mycoplasma arginini and Pseudomonas aeruginosa showed that the enzymes shared the same catalytic triad (Cys-His-Glu) and the Cys active site [26,27]. The catalytic region mainly located in the C-terminal region of ADI. To explore the effects of deleting the N-terminal non-catalytic fragment on solubility and activity of rADI, our construction based on pET30a-ADI, a plasmid that expressed a truncated ADI protein lacking the $\mathrm{N}$-terminal 30 amino acids (T-rADI, see Figure 1). Unfortunately, instead of improving solubility of the product, the truncation resulted in complete inactivation of the enzyme (Figure 2B, lanes $2 \& 4$ ).

\section{Co-expression with chaperone teams}

It is well known that chaperone proteins, such as DnaKDnaJ-GrpE and GroES-GroEL are efficient to assist protein folding. Thus, improve the production of active recombinant proteins $[1,6,28,29]$. We co-expressed the pET30a-ADI with four plasmids encoding different chaperone teams respectively. While pGro7 (expressing GroES-GroEL) and pG-KJE8 (expressing DnaK-DnaJGrpE and GroES-GroEL) had a similar effect to improve solubility of the rADI proteins, pKJE7 (expressing DnaKDnaJ-GrpE) and pTf16 (expressing Tig) didn't play any significant role to improve the solubility (Table 1). It suggested that only the GroES-GroEL chaperone team contributed to the improvement of soluble rADI proteins. For example, when the pET30a-ADI was co-expressed with pGro7, more rADI proteins formed as compared to the single pET30a-ADI plasmid that were present in the soluble part (Figure 2A, lane 5). The total activity was accordingly improved to $3.22 \pm 0.06 \mathrm{U} / \mathrm{ml}$, approximately 5-fold higher than that of the rADI expressed alone. However, the rADI proteins were still mostly in inclusion body forms (Figure 2A, lane 6). The further optimizations were performed based on the co-expression with pGro7.

\section{Cultivation-improved solubilization of rADI}

Kozai et al. [30] reported that the addition of L-arginine in the refolding solution was able to clearly increase the enzymatic activity of denatured ADI proteins. However, our experiments showed that the presence of L-arginine had no effect on the in-vitro solubilization of rADI proteins in the inclusion body form. We further tested whether L-arginine is helpful to improve the in vivo solubilization of ADI proteins in E. coli cells before the formation of inclusion bodies. E. coli cells are routinely cultivated in the LB medium, which contains peptones

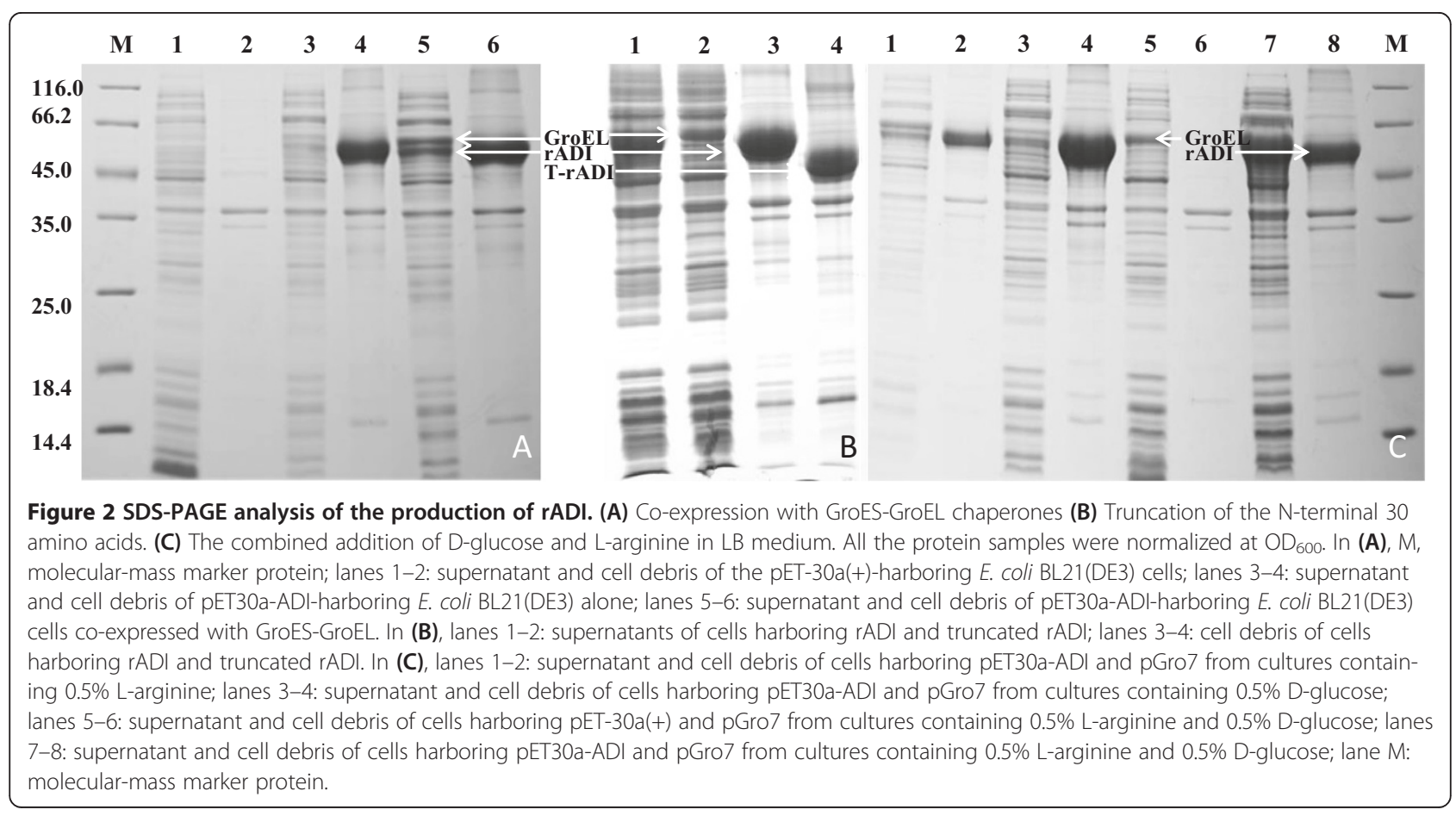


Table 1 The total activity of rADI co-expressed with different molecular chaperone

\begin{tabular}{cccccc}
\hline Plasmid & pET30a-ADI & + pG-KJE8 & + pGro7 & + pKJE7 & + pTf16 \\
\hline Total activity $(\mathrm{U} / \mathrm{ml})$ & $0.64 \pm 0.04$ & $3.14 \pm 0.15$ & $3.22 \pm 0.06$ & $0.60 \pm 0.08$ & $0.74 \pm 0.01$ \\
\hline
\end{tabular}

and yeast extracts as the carbon and nitrogen sources. We added different concentrations of L-arginine in the LB medium to cultivate the pET30a-ADI plasmid-harboring E. coli BL21(DE3) cells. Low concentrations of L-arginine (less than 1\%) had no effect on the solubilization of rADI proteins, while higher concentrations (1\%-5\%) caused alkalization of the medium (pH10.0), in which E. coli cells developed poorly or no growth at all. If we adjusted the media containing high L-arginine concentrations to $\mathrm{pH} 7.0$ or added L-arginine hydrochloride to replace Larginine, which did not change the $\mathrm{pH}$ of the medium significantly, E. coli cells were able to grow normally but the solubilization of rADI proteins did not improve.

The bacteria, such as Streptococcus lactis and Oenococcus oeni, that are able to utilize L-arginine as energy sources were unable to take up L-arginine in the absence of fermentable sugars [31-34]. We suggested that less amount of fermentable sugars in the LB medium might cause no effect of the addition of L-arginine on the solubilization of rADI proteins. Thus, we supplemented D-glucose together with L-arginine in the LB medium. Interestingly, the expression of soluble ADI proteins varied significantly with different concentrations of the supplements. The combination of $0.5 \% \mathrm{~L}$-arginine and $0.5 \% \mathrm{D}$-glucose gave the highest solubility of the protein (Figure $2 \mathrm{C}$ ), the enzymatic activity of the crude extracts reached $9.31 \pm 0.01$ to $9.43 \pm 0.02 \mathrm{U} / \mathrm{ml}$, which were much higher than that in the other combinations (Table 2). Under this condition, the yield of total and soluble rADI proteins were measured with the Bio-Rad' Image lab software, increased approximately 1.47 and 7.34-fold higher than that of the aloneexpressed rADI and 1.28 and 2.87-fold higher than that of the rADI co-expressed with pGro7 respectively. The total activity increased approximately 15 -fold higher than the rADI expressed alone $(0.64 \pm 0.04 \mathrm{U} / \mathrm{ml})$ and 3 -fold higher than that of the co-expression with pGro7 (3.16 \pm $0.02 \mathrm{U} / \mathrm{ml})$. In the absence of pGro7, the combination of $0.5 \% \mathrm{~L}$-arginine and $0.5 \% \mathrm{D}$-glucose also enhanced the total activity to $2.37 \pm 0.03 \mathrm{U} / \mathrm{ml}$.

It was noted that higher concentrations of D-glucose ( $1 \%$ or more) supported better growth of cells, but the activities of crude extracts were prominently decreased. Higher concentrations of supplemented L-arginine (1\% or more) inhibited the growth of cells because of alkalization of the medium, even with the presence of D-glucose, which caused no effect in the improvement of enzymatic activities (Table 2). For example, at the concentration of $1 \% \mathrm{~L}$-arginine (combined with $0.5 \% \mathrm{D}$-glucose), the $\mathrm{OD}_{600}$ of culture broth was less than 1.0 after 24 hrs of incubation and at the $2 \%$ concentration, there were no growth. Surprisingly, when we added different concentrations of L-arginine hydrochloride, instead of L-arginine in the LB medium with D-glucose, no improvement was observed for the solubilization of rADI proteins (Table 2). When L-arginine was combined with other sugars, such as D-galactose, D-sucrose and D-maltose, the solubilization of rADI proteins was not improved. When L-arginine was replaced with non-substrate amino acids of ADI, such as L-tryptophan, L-citrulline and L-glycine no improvement was observed for the solubilization of rADI proteins (Table 2).

We also assayed the effects of the combined addition of $0.5 \% \mathrm{~L}$-arginine and $0.5 \% \mathrm{D}$-glucose on the expression of another ADI, which was from Listeria welshimeri serovar 6b str. SLCC5334 (NC_008555). The total activity of the enzyme was $0.1187 \pm 0.04 \mathrm{U} / \mathrm{ml}$ in the presence of $0.5 \% \mathrm{~L}$-arginine and $0.5 \% \mathrm{D}$-glucose, which was 7.2 -fold higher than it expressed alone $(0.0165 \pm 0.01 \mathrm{U} / \mathrm{ml})$ and 2.9-fold higher than it co-expressed with pGro7 (0.0412 \pm $0.02 \mathrm{U} / \mathrm{ml}$ ). The increase rate was similar to that for the rADI from Pseudomonas putida. These results suggested that the combined addition of L-arginine and D-glucose was applicable in solubilization of different ADI proteins.

\section{Enzymatic and conversion characteristics of rADI}

After purification using Ni-NTA affinity chromatography, the recombinant proteins showed as a single band with a size of $53 \mathrm{kDa}$ on SDS-PAGE gel (Figure 3A). We assayed enzymatic characteristics of the purified rADI proteins. The rADI, which contained some additional terminal fragments such as a His-tag and some restriction sites, showed similar characteristics as the original ADI obtained from Pseudomonas putida [22]. For example, the stability of proteins was observed between $\mathrm{pH} 7.2$ and $\mathrm{pH} 9.0$ after 12 hrs incubation (Figure 3B). The optimal $\mathrm{pH}$ was 6.0 for enzymatic activity, but the activity was sharply decreased with the variation of $\mathrm{pH}$ value (above 7.2 or below 4.5) (Figure 3C). The enzymatic activity of rADI was mostly retained after incubation at $30^{\circ} \mathrm{C}$ or $40^{\circ} \mathrm{C}$ for $90 \mathrm{~min}$, clearly decreased after incubation at $50^{\circ} \mathrm{C}$ for $90 \mathrm{~min}$ (Figure 3D). $\mathrm{Cu}^{2+}(10 \mathrm{mM})$, SDS ( $1 \mathrm{mM}, 10 \mathrm{mM})$ and DTT $(1 \mathrm{mM}, 10 \mathrm{mM})$ strongly inhibited the activity of $\mathrm{rADI}, \mathrm{Cr}^{3+}(10 \mathrm{mM}), \mathrm{Co}^{2+}$ (10 $\mathrm{mM})$ had a slight inhibition for rADI, while other metal ions had no remarkable effect observed on rADI (Table 3). Interestingly, the suitable temperature for the enzymatic activity of rADI was between $30^{\circ} \mathrm{C}$ and $50^{\circ} \mathrm{C}$ and the optimal temperature was $40^{\circ} \mathrm{C}$ (Figure 3E). The 
Table 2 Effects of combined additions of different sugars and amino acids on the enzymatic activities of rADI condition optimization

\begin{tabular}{|c|c|c|c|c|}
\hline \multicolumn{4}{|c|}{ Combined addition $^{\mathrm{a}}$} & \multirow{2}{*}{$\begin{array}{c}\text { Enzymatic } \\
\text { activity }^{\mathrm{b}}(\mathrm{U} / \mathrm{ml})\end{array}$} \\
\hline Amino acid & Percentage & Sugar & Percentage & \\
\hline & & & $0 \%$ & $2.08 \pm 0.05$ \\
\hline & & & $0.5 \%$ & $9.43 \pm 0.02$ \\
\hline \multirow[t]{5}{*}{ L-arginine $0.5 \%$} & & D-glucose & $1 \%$ & $1.76 \pm 0.01$ \\
\hline & & & $2 \%$ & $1.60 \pm 0.06$ \\
\hline & & & $5 \%$ & $1.41 \pm 0.01$ \\
\hline & $0 \%$ & & & $2.78 \pm 0.02$ \\
\hline & $0.5 \%$ & & & $9.33 \pm 0.04$ \\
\hline \multirow[t]{5}{*}{ L-arginine } & $1 \%$ & \multicolumn{2}{|c|}{ D-glucose $0.5 \%$} & $0.86 \pm 0.04$ \\
\hline & $2 \%$ & & & $0.74 \pm 0.03$ \\
\hline & $5 \%$ & & & $0.70 \pm 0.05$ \\
\hline & $0 \%$ & & & $2.92 \pm 0.03$ \\
\hline & $0.5 \%$ & & & $2.93 \pm 0.05$ \\
\hline \multirow[t]{5}{*}{ L-arginine hydrochloride } & $1 \%$ & \multicolumn{2}{|c|}{ D-glucose $0.5 \%$} & $3.85 \pm 0.07$ \\
\hline & $2 \%$ & & & $4.35 \pm 0.02$ \\
\hline & $5 \%$ & & & $3.95 \pm 0.04$ \\
\hline & $0 \%$ & & & $3.18 \pm 0.03$ \\
\hline & $0.5 \%$ & & & $3.20 \pm 0.08$ \\
\hline \multirow[t]{5}{*}{ L-arginine hydrochloride } & $1 \%$ & \multicolumn{2}{|c|}{-} & $3.31 \pm 0.05$ \\
\hline & $2 \%$ & & & $3.60 \pm 0.02$ \\
\hline & $5 \%$ & & & $3.20 \pm 0.08$ \\
\hline & & - & - & $3.26 \pm 0.07$ \\
\hline & & D-glucose & $0.5 \%$ & $9.31 \pm 0.01$ \\
\hline \multirow[t]{3}{*}{ L-arginine $0.5 \%$} & & D-galactose & $0.5 \%$ & $2.35 \pm 0.04$ \\
\hline & & D-maltose & $0.5 \%$ & $1.96 \pm 0.04$ \\
\hline & & D-sucrose & $0.5 \%$ & $2.49 \pm 0.10$ \\
\hline- & - & & & $3.22 \pm 0.06$ \\
\hline L-arginine & $0.5 \%$ & & & $9.39 \pm 0.03$ \\
\hline L-tryptophan & $0.5 \%$ & \multicolumn{2}{|c|}{ D-glucose $0.5 \%$} & $1.93 \pm 0.06$ \\
\hline L-citrulline & $0.5 \%$ & & & $1.97 \pm 0.01$ \\
\hline L-glycine & $0.5 \%$ & & & $2.69 \pm 0.02$ \\
\hline
\end{tabular}

${ }^{a}$ : with the presence of $\mathrm{pGro} ;{ }^{\mathrm{b}}$ : produced from crude extracts.

optimal temperature was $50^{\circ} \mathrm{C}$ for the original ADI measured in Pseudomonas putida [22]. At the optimal $40^{\circ} \mathrm{C}$, the specific activity of $\mathrm{rADI}$ reached $76 \pm 0.03 \mathrm{U} / \mathrm{mg}$, which was also higher than $58.8 \mathrm{U} / \mathrm{mg}$ of the original at $50^{\circ} \mathrm{C}$.

We performed conversion experiments using the sodium phosphate buffer (500 mM, pH 6.0) containing $10 \%$ L-arginine. The L-citrulline products increased linearly at $30^{\circ} \mathrm{C}$ or $40^{\circ} \mathrm{C}$. After $22 \mathrm{hrs}$ of incubation, $20 \mathrm{~g}$ of L-arginine substrates were almost converted into Lcitrulline by the crude enzyme from $25 \mathrm{ml}$ cultures. The addition of the batch substrate or not, had no impact on the conversion (Figure 4). The above enzymatic characteristics suggested that rADI was a potential candidate for industrial conversion of L-arginine to Lcitrulline.

\section{Discussion}

Previously, it had been observed that the improvement of the substrate L-arginine for correct refolding of denatured ADI proteins in the refolding solution [30]. However, L-arginine had no effect on the in vitro solubilization of rADI proteins in inclusion body forms. Thus, in vivo solubilization is important for potential industrial applications of rADI proteins. In the laboratories, the $E$. coli cells are routinely cultivated in LB medium with 


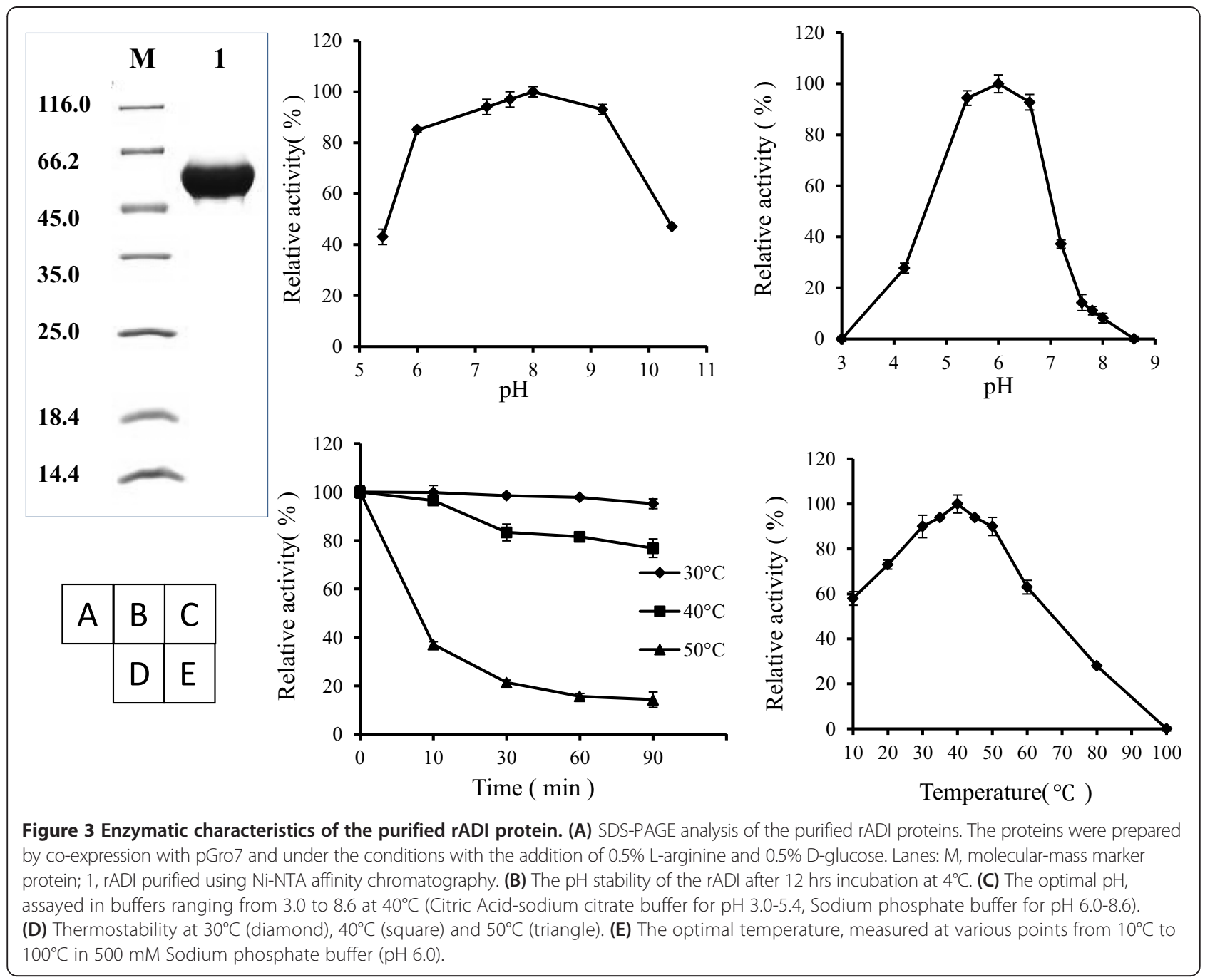

tryptone and yeast extracts as the carbon and nitrogen sources. The present study showed that the combined addition of L-arginine and D-glucose in the LB medium significantly improved in vivo solubilization of rADI proteins, but the addition of L-arginine or D-glucose alone did not have the effect. L-arginine have to enter E. coli cells to play the in vivo solubilization functions. We suggested that the functions of L-arginine in solubilization of $\mathrm{ADI}$ were probably via the binding to the proteins, thus preventing the formation of inclusion bodies.

The role of D-glucose is still unknown during this process. There are three possibilities of its roles: (1) Dglucose helped L-arginine to transport through the cell membrane (2) D-glucose balanced the medium $\mathrm{pH}$ (3) $\mathrm{D}$-glucose maintained the intracellular $\mathrm{pH}$ or metabolic processes. High concentrations of L-arginine caused alkalization of medium, which extensively inhibited the growth of cells. However, L-arginine hydrochloride did not change the medium $\mathrm{pH}$ significantly. The addition of the compound had no effect on the solubilization of the rADI proteins, even at low concentrations along with $\mathrm{D}$-glucose. Thus, balancing medium $\mathrm{pH}$ or intracellular $\mathrm{pH}$ is not the function of $\mathrm{D}$-glucose in the in vivo solubilization of rADI proteins.

Streptococcus lactis and Oenococcus oeni are able to utilize L-arginine as a source of energy via the $\mathrm{L}$-arginine catabolism pathway [33,34]. Poolman et al. [33] reported that $\mathrm{L}$-arginine entered these cells by an arginine-ornithine antiporter in S. lactis, which was initiated in the presence of a fermentable sugar. Only after initiated, L-arginine was able to subsequently enter cells via the ornithine and arginine concentration gradients formed during arginine metabolism [31,32]. It was suggested fermentable sugars provided the energy for the entrance of $\mathrm{L}$-arginine into cells. Bioinformatics analysis showed that the genome of E. coli BL21(DE3) (GenBank accession no. CP001509) had some predicted proteins related to the arginine-ornithine antiporter, such as an arginine/ornithine antiporter transporter, an arginine/ornithine transporter subunit and an arginine/ornithine transport system ATPase [35]. We 
Table 3 The effect of metal ions and reagents on the activity of rADI

\begin{tabular}{lcc}
\hline $\begin{array}{l}\text { Metal } \\
\text { ions/ } \\
\text { Reagents }\end{array}$ & \multicolumn{2}{c}{ Relative remaining activity (\%) of rADI } \\
\cline { 2 - 3 } Control & $100.0 \pm 2.9$ & $\mathbf{1 0 ~} \mathbf{~ m M}$ \\
$\mathrm{Li}^{+}$ & $99.6 \pm 2.5$ & $100.0 \pm 2.4$ \\
$\mathrm{Na}^{+}$ & $100.1 \pm 3.5$ & $100.5 \pm 0.8$ \\
$\mathrm{~K}^{+}$ & $104.1 \pm 2.5$ & $102.5 \pm 4.4$ \\
$\mathrm{Mg}^{2+}$ & $96.4 \pm 3.2$ & $100.1 \pm 4.9$ \\
$\mathrm{Ca}^{2+}$ & $96.2 \pm 3.9$ & $102.1 \pm 1.5$ \\
$\mathrm{Mn}^{2+}$ & $97.4 \pm 2.1$ & $91.2 \pm 2.4$ \\
$\mathrm{Cr}^{3+}$ & $98.1 \pm 2.3$ & $101.5 \pm 4.2$ \\
$\mathrm{Co}^{2+}$ & $94.9 \pm 2.8$ & $81.5 \pm 1.9$ \\
$\mathrm{Ni}^{2+}$ & $100.6 \pm 1.9$ & $73.7 \pm 2.5$ \\
$\mathrm{Cu}^{2+}$ & $80.2 \pm 1.2$ & $90.1 \pm 0.1$ \\
$\mathrm{EDTA}$ & $100.3 \pm 4.6$ & $33.6 \pm 1.5$ \\
$\mathrm{SDS}$ & $22.2 \pm 2.5$ & $94.9 \pm 1.8$ \\
$\mathrm{DTT}$ & $71.0 \pm 0.3$ & $4.9 \pm 1.6$ \\
\hline
\end{tabular}

supposed that the increased solubilization was associated with the in vivo interactions between L-arginine and newly synthesized rADI proteins during the process of refolding, which requires further determination.

\section{Conclusions}

Combined addition of L-arginine and D-glucose in the LB medium significantly improved in vivo solubility of rADI proteins but the addition of L-arginine or D-glucose alone did not have the effect. With the support of GroELGroES, the promotion of combined D-glucose and Larginine was more significant. The studies present in this paper suggested a new strategy to increase the solubilization of overexpressed recombinant proteins in E. coli cells.

\section{Methods}

Strains and cultivation conditions

E. coli DH5 $\alpha$ and BL21(DE3) strains (Table 4) were used as the hosts for cloning and expression of the ADI gene, respectively. The $E$. coli cells were routinely cultivated in Luria-Bertani (LB) medium (containing tryptone $10 \mathrm{~g} / \mathrm{L}$, yeast extract $5 \mathrm{~g} / \mathrm{L}$ and $\mathrm{NaCl} 10 \mathrm{~g} / \mathrm{L})$.

\section{Construction of recombinant plasmids}

The ADI gene studied in this study is taken from P. putida (GenBank accession no. P41142). We optimized the gene sequence according to the codon frequency table of $E$. coli BL21(DE3) using the "codon randomization" strategy [23]. The artificial gene and its corresponding amino acid sequences (Figure 1) were deposited in GenBank under the accession no. KJ411883. After synthesized at Biosune (Shanghai, China), the gene was amplified using a specific primer pair (Forward: CATGCCATGGCTATGAGCGCC GAAAAACAGAAGTATG; Reverse: CCCAAGCTTGATA ATCGATAGGGTCGCGAACAATG) to generate the digestion sites of endonucleases NcoI and HindIII (italics). After purification, the amplified fragment was digested using the restriction enzymes and ligated into plasmid pET-30a $(+)$, named pET30a-ADI, which was confirmed by

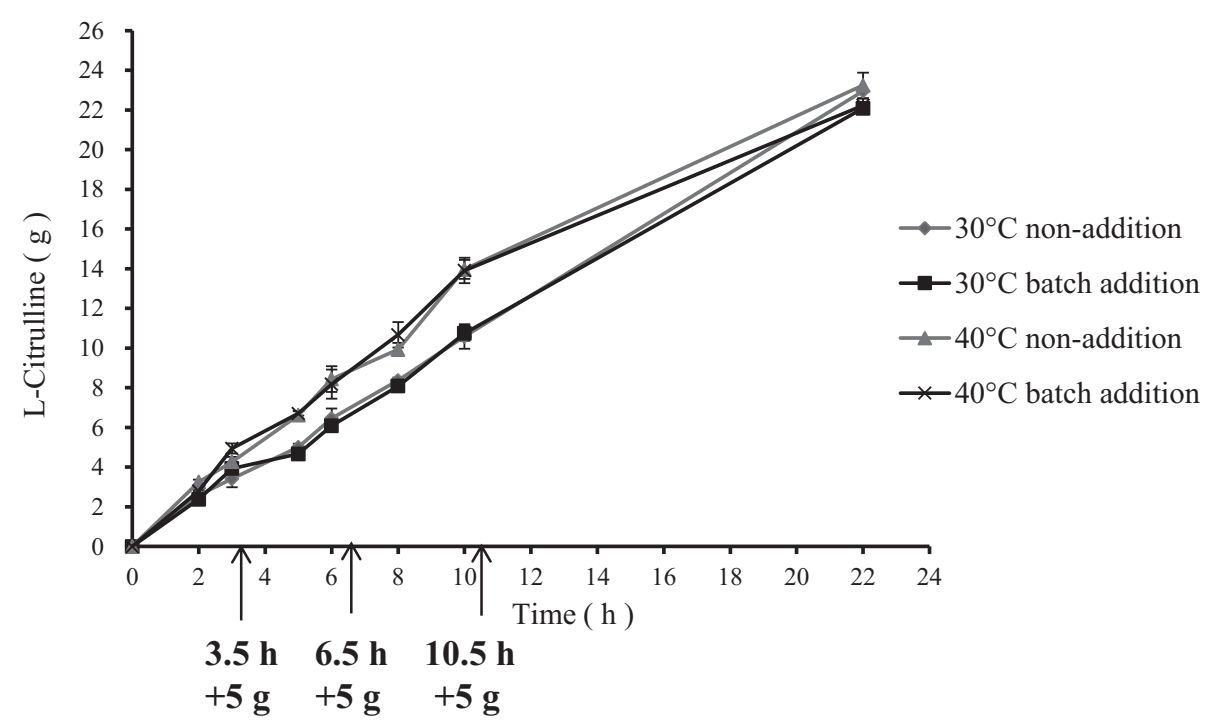

Figure 4 Conversation curves of L-arginine to L-citrulline by crude rADI enzymes. $20 \mathrm{~g}$ of L-arginine were added at the beginning (and - $\mathbf{\Lambda}$-) or batch-supplemented (---and - $\times-$ ) from $5 \mathrm{~g}$ to $20 \mathrm{~g}$ at different time points (indicated by black arrows). The conversation experiments were performed at $30^{\circ} \mathrm{C}$ and $40^{\circ} \mathrm{C}$. 
Table 4 Bacterial strains and plasmids used in this study

\begin{tabular}{|c|c|c|}
\hline Strains/plasmids & Genotype or description & Source \\
\hline \multicolumn{3}{|l|}{ Strains } \\
\hline E. coli DH5a & 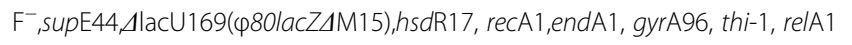 & Life Technologies \\
\hline E. coli BL21(DE3) & 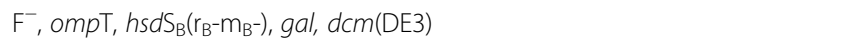 & Life Technologies \\
\hline \multicolumn{3}{|l|}{ Plasmids } \\
\hline pG-KJE8 & Encoding DnaK-DnaJ-GrpE / GroES-GroEL & Takara \\
\hline pGro7 & Encoding GroES-GroEL & Takara \\
\hline PKJE7 & Encoding DnaK-DnaJ-GrpE & Takara \\
\hline pTf16 & Encoding Tig & Takara \\
\hline pColdTF & Expression vector & Takara \\
\hline pET-30a $(+)$ & Expression vector & Novagen \\
\hline pGEX-6P-1 & Expression vector & GE Healthcare \\
\hline $\mathrm{pBAD} / \mathrm{g} \| \mathrm{II}$ & Expression vector & Invitrogen \\
\hline
\end{tabular}

sequencing. The construction of recombinant plasmids, transformation and protein expression were performed according to the protocol described by Sambrook and Russell [36].

\section{Co-expression with the chaperone teams}

The plasmids pGro7, pG-KJE8, pTf16 and pKJE7 encode different chaperone teams (Table 4). The pET30a-ADI was co-expressed with these four plasmids respectively. $E$. coli BL21(DE3) cells harboring plasmid pET30a-ADI alone or together with a chaperone-encoding plasmid were cultivated in $5 \mathrm{ml}$ of LB medium containing $40 \mu \mathrm{g} / \mathrm{ml} \mathrm{kana-}$ mycin and $20 \mu \mathrm{g} / \mathrm{ml}$ chloramphenicol for the selection of recombinants. After overnight shaking at $37^{\circ} \mathrm{C}$, the culture was inoculated (1\%) into fresh LB medium containing antibiotics and $0.04 \%$ L-arabinose (pG-KJE8 was induced by $5 \mu \mathrm{g} / \mathrm{ml}$ tetracycline and $0.04 \% \mathrm{~L}$-arabinose). The culture was shaken at $37^{\circ} \mathrm{C}$ to induce the expression of chaperones. When the $\mathrm{OD}_{600}$ of the culture reached $0.6-0.8$, isopropyl- $\beta$-D-thiogalactopyranoside (IPTG) was added to a final concentration of $0.1 \mathrm{mM}$ to induce the expression of rADI. After additional $24 \mathrm{hrs}$ of incubation at $16^{\circ} \mathrm{C}$, the cells were harvested by centrifugation at $8,000 \times g$ and $4^{\circ} \mathrm{C}$ for $10 \mathrm{~min}$. The cell pellets were washed, resuspended in Tris- $\mathrm{NaCl}$ buffer (50 mM Tris, $150 \mathrm{mM} \mathrm{NaCl}, \mathrm{pH}$ 8.0) and broken by sonication on ice. After centrifugation at $12,000 \times g$ and $4^{\circ} \mathrm{C}$ for $30 \mathrm{~min}$, the separated supernatant and cell debris were assayed enzymatic activities and in sodium dodecyl sulfate-polyacrylamide gel electrophoresis (SDS-PAGE, 10\% gel concentration).

\section{Cultivation-improved solubilization of rADI}

The E. coli BL21(DE3) cells harboring the combined plasmids of pET30a-ADI and pGro7 were cultivated as described above. To assay the effects of cultivation on the solubility of rADI, different saccharides (D-glucose, $\mathrm{D}$-sucrose, D-galactose or D-maltose) were added to a final concentration of $0.5 \%$ in the LB medium containing the antibiotics and L-arabinose. Together with the addition of IPTG, different amino acids (L-arginine, L-tryptophan, L-citrulline and L-glycine) were added to a final concentration of $0.5 \%$ when the culture $\mathrm{OD}_{600}$ reached 0.6-0.8. The cultures were incubated for additional $24 \mathrm{hrs}$ at $16^{\circ} \mathrm{C}$. E. coli BL21(DE3) harboring pET-30a(+) was used as negative control.

\section{Purification of rADI}

After harvested, cells were broken by sonication, and the supernatants were applied to the Ni-NTA affinity chromatography (GE Healthcare, Buckinghamshire, U.K.) to purify rADI. The protein concentration was determined using the Bradford method (Bio-Rad, Munich, Germany). Different fractions were collected and assayed enzymatic activities and in SDS-PAGE (10\%).

\section{Activity assays of rADI}

The rADI activity was determined using a modified method of diacetyl monoxime thiosemicarbazide [17,37]. $40 \mathrm{mM}$ L-arginine was dissolved in $500 \mathrm{mM}$ sodium phosphate buffer ( $\mathrm{pH}$ 6.0). After the addition of rADI, the mixture was incubated at $40^{\circ} \mathrm{C}$ for $10 \mathrm{~min}$. Then, acid-ferric solution (containing $15 \% \mathrm{H}_{2} \mathrm{SO}_{4}, 60 \% \mathrm{H}_{3} \mathrm{PO}_{4}$ and $0.005 \%$ $\mathrm{FeCl}_{3}$ ) and DAM-TSC solution (containing 1\% diacetyl monoxime and $0.06 \%$ thiosemicarbazide) were added to stop the reaction and the mixture was heated at $100^{\circ} \mathrm{C}$ for $10 \mathrm{~min}$ for coloration. The amount of L-citrulline was evaluated by measuring the optical density at $530 \mathrm{~nm}$. The protein concentration was determined using Bradfordassay with bovine serum albumin as standard. One unit of the ADI activity was defined as the amount of enzymes to produce one $\mu \mathrm{mol} \mathrm{L}$-citrulline per minute under the assay conditions. All the assays were performed in triplicate. The total enzymatic activity was defined as units per 
milliliter of culture and the specific enzymatic activity was shown as units per milligram of purified enzyme.

\section{Conversion rate of crude enzyme}

The crude enzymes were prepared from sonicationbroken cells using the above-described methods. $20 \mathrm{ml}$ crude extracts from $100 \mathrm{ml}$ culture broth were divided into four equal parts. The conversion of L-arginine to L-citrulline was assayed in $200 \mathrm{ml}$ reaction buffer (500 $\mathrm{mM}$ sodium phosphate buffer, $\mathrm{pH} 6.0$ ) at $30^{\circ} \mathrm{C}$ or $40^{\circ} \mathrm{C}$. $20 \mathrm{~g} \mathrm{~L}$-arginine was added at the beginning or batch-supplemented from $5 \mathrm{~g}$ to $20 \mathrm{~g}$ at different time points.

\section{Competing interests}

The authors declare that they have no competing interests.

\section{Authors' contributions}

YZL and YW designed the experiments and analyzed the data. YW performed all the experiments. YZL and YW wrote the paper. Both authors read and approved the final manuscript.

\section{Acknowledgements}

This work was financially supported by the National Natural Science Foundation of China (NSFC) Key Program (No. 31130004) and the NSFC for Distinguished Young Scholars (No. 30825001).

Received: 20 March 2014 Accepted: 3 June 2014

Published: 7 June 2014

\section{References}

1. Georgiou G, Valax P: Expression of correctly folded proteins in Escherichia coli. Curr Opin Biotechnol 1996, 7:190-197.

2. Baneyx F, Mujacic M: Recombinant protein folding and misfolding in Escherichia coli. Nat Biotechnol 2004, 22:1399-1408.

3. Gasser B, Saloheimo M, Rinas U, Dragosits M, Rodriguez-Carmona E, Baumann K, Giuliani M, Parrilli E, Branduardi P, Lang C, Porro D, Ferrer P, Tutino ML, Mattanovich D, Villaverde A: Protein folding and conformational stress in microbial cells producing recombinant proteins: a host comparative overview. Microb Cell Fact 2008, 7:11.

4. Frokjaer $\mathrm{S}$, Otzen DE: Protein drug stability: a formulation challenge. Nat Rev Drug Discov 2005, 4:298-306.

5. Schrodel A, de Marco A: Characterization of the aggregates formed during recombinant protein expression in bacteria. BMC Biochem 2005, 6:10.

6. Platas G, Rodriguez-Carmona E, Garcia-Fruitos E, Cano-Garrido O, Villaverde A: Co-production of GroELS discriminates between intrinsic and thermally-induced recombinant protein aggregation during substrate quality control. Microb Cell Fact 2011, 10:79.

7. Sorensen HP, Mortensen KK: Advanced genetic strategies for recombinant protein expression in Escherichia coli. J Biotechnol 2005, 115:113-128.

8. de Marco A, Deuerling E, Mogk A, Tomoyasu T, Bukau B: Chaperone-based procedure to increase yields of soluble recombinant proteins produced in E. coli. BMC Biotechnol 2007, 7:32.

9. Zuniga M, Perez G, Gonzalez-Candelas F: Evolution of arginine deiminase (ADI) pathway genes. Mol Phylogenet Evol 2002, 25:429-444.

10. Ni Y, Schwaneberg U, Sun ZH: Arginine deiminase, a potential anti-tumor drug. Cancer Lett 2008, 261:1-11.

11. Takaku H, Takase M, Abe S, Hayashi H, Miyazaki K: In vivo anti-tumor activity of arginine deiminase purified from Mycoplasma arginini. Int J Cancer 1992, 51:244-249.

12. Misawa S, Aoshima M, Takaku H, Matsumoto M, Hayashi H: High-level expression of Mycoplasma arginine deiminase in Escherichia coli and its efficient renaturation as an anti-tumor enzyme. J Biotechnol 1994, 36:145-155.

13. Kakimoto T, Shibatani T, Nishimura N, Chibata I: Enzymatic production of L-citrulline by Pseudomonas putida. Appl Microbiol 1971, 22:992-999.
14. Miyazaki K, Takaku H, Umeda M, Fujita T, Huang WD, Kimura T, Yamashita J, Horio T: Potent growth inhibition of human tumor cells in culture by arginine deiminase purified from a culture medium of a Mycoplasmainfected cell line. Cancer Res 1990, 50:4522-4527.

15. Takaku H, Misawa S, Hayashi H, Miyazaki K: Chemical modification by polyethylene glycol of the anti-tumor enzyme arginine deiminase from Mycoplasma arginini. Jpn J Cancer Res 1993, 84:1195-1200.

16. Takaku H, Matsumoto M, Misawa S, Miyazaki K: Anti-tumor activity of arginine deiminase from Mycoplasma arginini and its growth-inhibitory mechanism. Jpn J Cancer Res 1995, 86:840-846.

17. Liu YM, Sun ZH, Ni Y, Zheng P, Liu YP, Meng FJ: Isolation and identification of an arginine deiminase producing strain Pseudomonas plecoglossicida CGMCC2039. World J Microbiol Biotechnol 2008, 24:2213-2219.

18. Kim JE, Jeong DW, Lee HJ: Expression, purification, and characterization of arginine deiminase from Lactococcus lactis ssp. lactis ATCC 7962 in Escherichia coli BL21. Protein Expr Purif 2007, 53:9-15.

19. Burne RA, Parsons DT, Marquis RE: Cloning and expression in Escherichia coli of the genes of the arginine deiminase system of Streptococcus sanguis NCTC 10904. Infect Immun 1989, 57:3540-3548.

20. Knodler LA, Schofield PJ, Gooley AA, Edwards MR: Giardia intestinalis: purification and partial amino acid sequence of arginine deiminase. Exp Parasitol 1997, 85:77-80.

21. Knodler LA, Sekyere EO, Stewart TS, Schofield PJ, Edwards MR: Cloning and expression of a prokaryotic enzyme, arginine deiminase, from a primitive eukaryote Giardia intestinalis. J Biol Chem 1998, 273:4470-4477

22. Shibatani T, Kakimoto T, Chibata I: Crystallization and properties of L-arginine deiminase of Pseudomonas putida. J Biol Chem 1975, 250:4580-4583.

23. Menzella HG: Comparison of two codon optimization strategies to enhance recombinant protein production in Escherichia coli. Microb Cell Fact 2011, 10:15.

24. Donovan RS, Robinson CW, Glick BR: Review: optimizing inducer and culture conditions for expression of foreign proteins under the control of the lac promoter. J Ind Microbiol 1996, 16:145-154.

25. Wen TN, Chen JL, Lee SH, Yang NS, Shyur LF: A truncated Fibrobacter succinogenes 1,3-1,4-beta-d-glucanase with improved enzymatic activity and thermotolerance. Biochemistry (Mosc) 2005, 44:9197-9205.

26. Das K, Butler GH, Kwiatkowski V, Clark AD Jr, Yadav P, Arnold E: Crystal structures of arginine deiminase with covalent reaction intermediates: mplications for catalytic mechanism. Structure 2004, 12:657-667

27. Lu X, Galkin A, Herzberg O, Dunaway-Mariano D: Arginine deiminase uses an active-site cysteine in nucleophilic catalysis of L-arginine hydrolysis. J Am Chem Soc 2004, 126:5374-5375.

28. Nishihara K, Kanemori M, Kitagawa M, Yanagi H, Yura T: Chaperone coexpression plasmids: differential and synergistic roles of DnaK-DnaJGrpE and GroEL-GroES in assisting folding of an allergen of Japanese cedar pollen, Cryj2, in Escherichia coli. Appl Environ Microbiol 1998, 64:1694-1699.

29. Yan X, Hu S, Guan YX, Yao SJ: Coexpression of chaperonin GroEL/GroES markedly enhanced soluble and functional expression of recombinant human interferon-gamma in Escherichia coli. Appl Microbiol Biotechnol 2012, 93:1065-1074.

30. Kozai M, Sasamori E, Fujihara M, Yamashita T, Taira H, Harasawa R: Growth inhibition of human melanoma cells by a recombinant arginine deiminase expressed in Escherichia coli. J Vet Med Sci 2009, 71:1343-1347.

31. Liu SQ, Pilone GJ: A review: arginine metabolism in wine lactic acid bacteria and its practical significance. J Appl Microbio/ 1998, 84:315-327.

32. Liu SQ, Pritchard GG, Hardman MJ, Pilone GJ: Arginine catabolism in wine lactic acid bacteria: is it via the arginine deiminase pathway or the arginase-urease pathway? J Appl Bacteriol 1996, 81:486-492.

33. Poolman B, Driessen AJ, Konings WN: Regulation of arginine-ornithine exchange and the arginine deiminase pathway in Streptococcus lactis. J Bacteriol 1987, 169:5597-5604

34. Tonon T, Lonvaud-Funel A: Metabolism of arginine and its positive effect on growth and revival of Oenococcus oeni. J App/ Microbiol 2000, 89:526-531

35. Jeong $\mathrm{H}$, Barbe V, Lee CH, Vallenet $\mathrm{D}$, Yu DS, Choi SH, Couloux A, Lee SW, Yoon SH, Cattolico L, Hur CG, Park HS, Segurens B, Kim SC, Oh TK, Lenski RE, 
Studier FW, Daegelen P, Kim JF: Genome sequences of Escherichia coli B strains REL606 and BL21(DE3). J Mol Biol 2009, 394:644-652.

36. Sambrook J, Russell DW, Sambrook J: The Condensed Protocols from Molecular Cloning: A Laboratory Manual. Cold Spring Harbor, N.Y.: Cold Spring Harbor Laboratory Press; 2006.

37. Ni Y, Liu Y, Schwaneberg U, Zhu L, Li N, Li L, Sun Z: Rapid evolution of arginine deiminase for improved anti-tumor activity. Appl Microbiol Biotechnol 2011, 90:193-201.

doi:10.1186/1472-6750-14-53

Cite this article as: Wang and Li: Cultivation to improve in vivo solubility of overexpressed arginine deiminases in Escherichia coli and the enzyme characteristics. BMC Biotechnology 2014 14:53.

\section{Submit your next manuscript to BioMed Central and take full advantage of:}

- Convenient online submission

- Thorough peer review

- No space constraints or color figure charges

- Immediate publication on acceptance

- Inclusion in PubMed, CAS, Scopus and Google Scholar

- Research which is freely available for redistribution 